\title{
Matemática é Matemática, ou tem Matemática do Campo?
}

Línlya Sachs

\section{Resumo}

A discussão pretendida neste artigo está expressa no título: "matemática é matemática, ou tem matemática do campo?”. Em outras palavras, a proposta está em problematizar a questão em torno do conhecimento matemático e sua especificidade na educação do campo. Para defender a tese de que, sim, há matemática do campo, são considerados os pressupostos teóricos da Etnomatemática e das ideias presentes no Modelo dos Campos Semânticos. Por um lado, a Etnomatemática considera como conhecimento o que, rotineiramente, não é reconhecido como tal. Também, ela coloca em debate o aspecto político envolvido no que se entende por matemática. Por outro lado, o Modelo dos Campos Semânticos conceitua alguns termos importantes para esta pesquisa, como conhecimento e legitimidade. A especificidade da educação do campo, ainda, abre espaço para essa matemática, específica, do campo. O texto traz, então, duas abordagens pedagógicas possíveis nesse cenário. A primeira delas - bastante recorrente na literatura - é partir desse outro conhecimento - a matemática do campo - para atingir o conhecimento presente nos currículos escolares - a matemática escolar. A segunda possibilidade é a do reconhecimento da diferença entre conhecimentos, sem hierarquizá-los ou diminuir a legitimidade de um deles, havendo, então, o reconhecimento de que há matemática do campo e que esse modo de produção de significados é legítimo em seu contexto - e que pode, também, ser abordada pelos professores em suas aulas de matemática. Por fim, o artigo traz o espaço (não) destinado a essa matemática do campo, em cursos para formação de professores, específicos para o campo.

Palavras-chave: Educação Matemática. Educação do Campo. Etnomatemática. Conhecimento. 


\section{Mathematics is Mathematics otherwise is there Rural Mathematics?}

Línlya Sachs

Abstract

The proposed discussion of this paper is expressed in the title: "mathematics is mathematics otherwise is there rural mathematics?”. In other words, the aim is to discuss the mathematical knowledge and its specificity in the rural education. To defend the thesis that, yes, there is rural mathematics, they are considered the theoretical assumptions of the Ethnomathematics and some ideas of the Model of Semantic Fields. On the one hand, the Ethnomathematics considers as knowledge which routinely is not recognized as such. In addition, it puts under discussion the political aspects involved in what mathematics means. On the other hand, the Model of Semantic Fields conceptualizes some important terms for this research, as knowledge and legitimacy. The specificity of the rural education allows say about the rural mathematics, specific. This paper shows, then, two possible pedagogical approaches. The first - frequent in the literature - is from that other knowledge - rural mathematics - to achieve the curricular knowledge mathematics of the school. The second possibility is the recognition of the difference between knowledge, without organizing them hierarchically or decrease the legitimacy of one of them, having then the recognition that there is rural mathematics and that meaning production mode is legitimate in its context - and the teachers can do it in their math classes. Finally, the article provides the (no) space for this rural mathematics, in courses for teacher training, specific to the rural schools.

Keywords: Mathematics Education. Rural Education. Ethnomathematics. Knowledge. 


\title{
Iniciando a conversa
}

A discussão que proponho aqui está expressa no título do texto: "matemática é matemática, ou tem matemática do campo?”. Em outras palavras, quero problematizar a questão em torno do conhecimento matemático e sua especificidade na educação do campo.

Essa temática surgiu para mim durante minha pesquisa de doutorado, em que entrevistei pessoas ligadas, de alguma forma, à educação do campo. Entre elas, estava um pesquisador da área, doutor em Educação. Entre várias questões que fiz a ele, perguntei o que deveria ser diferente na formação de professores para atuar em escolas do campo, como nos cursos de Licenciatura em Educação do Campo. Sua resposta foi a seguinte:

\begin{abstract}
Fazer com que os alunos ou [...] os educadores em formação tenham uma base grande do que é o campo. Porque se eu vou ensinar Matemática, na educação do campo, Matemática é Matemática, ou tem Matemática do Campo? Ou eu utilizo o instrumental matemático, para responder alguns problemas que se apresentam no campo? Então, eu parto dessa ideia de que não são saberes diferentes que as pessoas do campo têm que ter, não é isso. É a capacidade que os professores têm que ter de utilizar aquele meio para ensinar aos alunos matemática, português e assim por diante (BARBOSA, 2014, p. 155, grifos meus).
\end{abstract}

Essa fala em destaque pareceu a mim indicar uma discussão pouco feita no âmbito da Educação Matemática, mas que é essencial ao se pensar em educação do campo e em currículo nesses contextos. Diante disso, coloco em discussão se existe uma matemática do campo como objetivo deste artigo.

Para conseguir responder à questão colocada pelo pesquisador, preciso situar teoricamente a discussão que faço aqui. Para tal, valho-me dos pressupostos da Etnomatemática e das ideias presentes no Modelo dos Campos Semânticos. Com isso, defendo a tese de que, sim, há matemática do campo. Ainda, sigo abordando as consequências desse entendimento na educação do campo, no que se refere a propostas pedagógicas e a formação de professores.

\section{Que matemática é essa? Matemática do campo?}

Para entender que matemática é essa que falo, fundamento-me teoricamente na Etnomatemática e no Modelo dos Campos Semânticos.A Etnomatemática dá importante sustentação para esse tipo de discussão, pois considera como conhecimento o que, rotineiramente, não é reconhecido como tal. Como afirma D’Ambrosio (2004), ao explicar o Programa Etnomatemático, o interesse está em “[...] entender o fazer e o saber matemático de culturas marginalizadas" (p. 44) e em "entender o ciclo de geração, organização intelectual, organização social e difusão desse conhecimento” (p. 45).

Esse conhecimento matemático difere-se do que é chamado de "matemática" nos contextos escolares e acadêmicos. A questão que permeia este texto é: em que se difere? 
Knijnik (2004, s/p) ressalta a existência de outras matemáticas:

[...] para sermos mais precisos, deveríamos dizer que aquilo que chamamos tradicionalmente de Matemática é a Matemática acadêmica. Na perspectiva da Etnomatemática, existem também outras formas de produzir significados matemáticos, outras formas que são igualmente Etnomatemáticas, pois manifestações simbólicas de grupos culturais.

Diversas pesquisas em Etnomatemática têm mostrado essas outras matemáticas. É o caso do trabalho de Knijnik (2006), ao apresentar os modos de cubação da terra por agricultores. A matemática escolar não faz sentido para as situações reais; a lógica é outra; a matemática é outra. Ela apresenta o Método do Jorge e o Método do Adão, que não são menos importantes que a Fórmula de Heron - está presente em currículos escolares, mas menos eficaz que os anteriores para as situações de medição de terra dos assentamentos rurais. BOCASANTA (2016) também explora essas outras matemáticas, quando aborda a lógica de crianças catadoras ao "comprar um real de pão" - diferente da lógica presente em livros didáticos quando "os personagens compram alimentos em função da quantidade de que necessitam - muitas vezes em grandes quantidades -, não demonstrando apresentar limitações de cunho econômico" (p. 70).

Ainda, há o aspecto político a ser levado em consideração quando se trata da Etnomatemática. Dar voz a outros conhecimentos, reconhecendo suas complexidades e respeitando suas especificidades é uma questão de escolha - e escolhas são políticas. Knijnik (2004, s/p) explica a politicidade nesse campo com clareza:

É neste sentido que considero a importância do pensamento etnomatemático, que problematiza a cientificidade, a neutralidade e assepsia da Matemática acadêmica e traz à cena as "outras" Matemáticas, usualmente silenciadas na escola, enquanto produção cultural de grupos não hegemônicos. Esta não é, no entanto, uma mera atitude de "benevolência" para com os excluídos. [...] Nosso papel nestes processos de inclusão ou exclusão de conhecimentos no currículo escolar é, antes de tudo, e sobretudo, político. Tais processos, definindo quais grupos estarão representados e quais estarão ausentes na escola são, ao mesmo tempo, produto de relações de poder e produtores destas relações: produto de relações de poder, pois são os grupos dominantes que têm o capital cultural para definir quais os conhecimentos que são legítimos para integrar o currículo escolar; são também produtores de relações de poder, porque influem, por exemplo, no sucesso ou fracasso escolar, produzem subjetividades muito particulares, posicionando as pessoas em determinados lugares do social e não em outros. Estes lugares não estão, de uma vez por todas, definidos. O campo da Educação Matemática é também um campo possível de contestação. Por isto, político.

Desse modo, a Etnomatemática tem um papel fundamental na discussão proposta neste texto. Por um lado, por reconhecer outros conhecimentos como tais e, por outro lado, por colocar em debate o aspecto político envolvido no que se entende por matemática.

Com relação ao Modelo dos Campos Semânticos, baseio-me nos trabalhos de Romulo Campos Lins. Ele situa o desenvolvimento do modelo: 
As primeiras ideias do MCS [Modelo dos Campos Semânticos] são de 1986 ou 1987. Eu tinha muitas inquietações e perguntas relacionadas à sala de aula, sempre coisa de professor mesmo, e que os autores que eu lia não me ajudavam a tratar. Em particular, queria dar conta de caracterizar o que os alunos estavam pensando quando "erravam", mas sem recorrer a esta ideia do erro. Por exemplo, somar frações somando numeradores e somando denominadores; certamente eles não fazem isto devido a um curto-circuito cerebral, de forma fortuita. Eles estavam pensando em alguma coisa, e eu queria poder tratar destas outras coisas do mesmo modo (com o mesmo referencial teórico) que as coisas "certas" (LINS, 2012, p. 11, grifo do autor).

Para tal, o autor conceitua alguns termos e é a partir deles que apresenta os novos modos de entendimento das coisas em geral e de suas consequências na educação. Aqui, limito-me a apenas alguns deles. Um desses termos é central neste artigo: conhecimento. A definição dada pelo autor difere da que se encontra na literatura ou nos dicionários filosófico, etimológico ou de língua portuguesa. Por exemplo, o Dicionário Houaiss apresenta, entre outras acepções, estas: "ato de perceber ou compreender por meio da razão e/ou da experiência” e "domínio, teórico ou prático, de uma arte, uma ciência, uma técnica etc." (HOUAISS, 2009, s/p).

Já para Lins (2012, p. 12), “um conhecimento consiste em uma crença-afirmação (o sujeito enuncia algo em que acredita) junto com uma justificação (aquilo que o sujeito entende como lhe autorizando a dizer o que diz)". Nota-se que, para o autor, diferente de outras definições encontradas, o conhecimento existe a partir de uma enunciação (crençaafirmação) e de uma justificação.Algumas explicações são feitas:

Um conhecimento não é nem mais, nem menos, que isto. Existe em sua enunciação e deixa de existir quando ela termina. A justificação é parte constitutiva de um conhecimento, assim como aquilo que é afirmado e a crença no que é afirmado; isto quer dizer que o que constitui um conhecimento são estes três elementos. [...]

A justificação deve ser parte constitutiva de um conhecimento (e não apenas um acessório para se verificar se o sujeito tem o direito de dizer que conhece isto ou aquilo). É assim porque de outro modo não é possível distinguir o conhecimento de uma criança e de um matemático quando dizem “ $2+4=4+2$ ”, e isso não seria bom (LINS, 2012, p. 12, grifos do autor).

No exemplo dado pelo autor, ele fala sobre a diferença entre o conhecimento de um matemático e o conhecimento de uma criança quando fazem a mesma enunciação: “2+4=4+2". O matemático, possivelmente, apresente uma justificação do tipo: "pela propriedade da comutatividade para a adição de números naturais, garantimos que os resultados são iguais". Já a criança pode fazer sua justificação da seguinte forma: "se eu tenho duas balas e junto com quatro balas, terei seis balas; se eu fizer o contrário, tendo, primeiro, quatro balas e juntar com duas, também terei seis balas”. Para o Modelo dos Campos Semânticos, por ser a justificação parte constitutiva do conhecimento, esses 
conhecimentos não são o mesmo, ainda que o matemático e a criança façam a mesma afirmação.

É importante distinguir o termo justificação daquilo que se costuma entender por justificativa, em textos matemáticos. Para isso, utilizo um exemplo de conhecimento como sendo o par formado, respectivamente, pela crença-afirmação e pela justificação: " $E=m c^{2}$ " $\mathrm{e}$ "Li num livro que Einstein provou isso" (LINS; GIMENEZ, 1997, p. 142). Nesse caso, a justificação não fala "sobre" a crença-afirmação - como se esperaria de uma justificativa matemática - mas garante que ela possa ser enunciada. É aí que está presente a ideia de legitimidade.

Em um contexto de discussão informal entre amigos, a enunciação " $E=m c^{2}$ ", com a justificação "Li num livro que Einstein provou isso", pode ser legítima. Já, em uma situação em que um estudante de um curso de Física fosse solicitado por seu professor, em uma prova, a demostrar que $E=m c^{2}$, essa enunciação com essa justificação não seriam legítimas. Assim, outro conhecimento seria necessário, pois a direção em que se fala é outra. Como afirma Lins (2012, p. 13, grifos do autor), “[...] nenhum conhecimento vem ao mundo ingenuamente. Aquele que o produz, que o enuncia, já fala em uma direção (o interlocutor) na qual o que ele diz, e com a justificação que tem, pode ser dito"Lins (2012, p. 22, grifos do autor) complementa:

A luta pelo poder dentro de culturas (sociedades) se dá na forma do controle de quais são os modos de produção de significados legítimos; é nisto que ela é simbólica. [...] A luta pelo controle de quais são os modos de produção de significados legítimos é o próprio processo de determinação de horizontes culturais (as fronteiras). O silêncio, o riso, a reprovação escolar, a excomunhão, a internação psiquiátrica, são algumas formas de se negar legitimidade a dados modos de produção de significado.

Assim, estabeleço uma relação entre o Modelo dos Campos Semânticos, a partir das noções de conhecimento e legitimidade, e a Etnomatemática - ou o Programa Etnomatemático, enquanto programa de pesquisa - parece ter dado, por meio das pesquisas realizadas e do campo que abriu, legitimidade a outros modos de produção de significado para aquilo que se chama matemática. A última frase da citação acima escancara um fato: qualquer conhecimento que não seja mais ou menos próximo da matemática escolar é motivo de riso e chacota em uma sala de aula.

Imaginemos a seguinte situação: um professor de matemática, cheio de boas intenções, tentando "trazer a 'realidade" para suas aulas, ao ensinar divisão, pergunta aos estudantes: se, em um assentamento rural, a conta de luz de uma bomba d'água, usada coletivamente pelos duzentos moradores, vem no valor de quatrocentos reais, quanto cada um deve pagar? O professor, com o seu conhecimento, possivelmente espere como resposta algo como: cada morador deve pagar dois reais, pois quatrocentos dividido por duzentos 
resulta em dois. Mas, imaginemos a seguinte resposta vinda de um estudante: "Eu pego a conta, pego o valor comum (taxa básica) e divido entre os que usaram. Depois, o que sobrou eu divido conforme cada um pode pagar. Se alguém teve prejuízo e outro lucro, então aquele que teve lucro paga uma parcela um pouco maior" (MONTEIRO, 2004, p. 443). Esse conhecimento seria aceito na aula de matemática? O modo de produção de significados desse estudante seria legítimo?

Esse é um caso de pesquisa em Etnomatemática e um modo de produção de significados da realidade de um assentamento rural. Como afirma Monteiro (2004), esse tipo de cálculo seria desprezado no contexto escolar, por utilizar a calculadora e por se basear em princípios de solidariedade: “[...] na escola a divisão é tratada somente como uma conta, como um algoritmo a ser ensinado. [...] Porém, a situação acima, recheada de vida, não fala apenas de uma divisão, fala de critérios de divisão, fala da razão pela qual devemos dividir e dos valores envolvidos nessa prática” (p. 443).

Essa situação fictícia - mas baseada em fatos reais! - explicita a diferença entre um conhecimento e outro. Lins e Gimenez (1997) abordam as diferenças entre a matemática da rua e a matemática da escola e afirmam que cada uma envolve seus próprios significados e procedimentos, sendo que essas diferenças constituem legitimidades, "pois do mesmo modo que a escola proíbe os métodos da rua - em geral chamando-os de informais e, dizendo que são de aplicação limitada -, a rua proíbe os métodos da escola, chamando-os de complicados e sem significado, e dizendo que não são necessários na rua” (p. 17).

Neste texto, refiro-me a esse outro conhecimento como a matemática do campo, em referência à fala do pesquisador entrevistado.

\section{Matemática do campo na escola do campo}

Considerando, então, a existência de uma matemática do campo, o que o professor poderia fazer com ela em uma escola do campo? Antes de apresentar possibilidades pedagógicas nesse sentido, explico por que uso a locução adjetiva do campo, ao invés do adjetivo rural - seja para escola, para educação ou para matemática.

É preciso situar historicamente a educação do campo para que essa explicação faça sentido. A exclusão no acesso à educação por aqueles que moram e trabalham no meio rural é alarmante e está associada à exclusão de outros direitos básicos. Diversos dados revelam a precariedade de vida no meio rural, seja pela concentração de terras, seja pelos baixos salários e condições degradantes de trabalho, seja pela falta de escolaridade.

No que se refere ao acesso à educação, Leite (1999) apresenta as políticas públicas implantadas no país desde o século XIX até o fim do século XX e mostra que a educação sempre foi negada ao homem do campo, como meio para a obtenção de mão de obra barata e desqualificada para o trabalho na agricultura. Não é à toa que a expressão educação rural 
sempre esteve associada a educação de má qualidade. Um exemplo disso é a fala de Peraino(2007), que, ao analisar o caso de um estudante com alto desempenho e destaque em uma competição matemática, indica o fato de ele estudar em uma escola rural como um "apesar".

Um estudo produzido pelo Instituto Nacional de Estudos e Pesquisas Educacionais Anísio Teixeira (INEP, 2007) apontou as principais características das escolas rurais: problemas de infraestrutura, de transporte de professores e de estudantes, falta de professores com formação, currículo centrado em questões urbanas, turmas multisseriadas, elevadas taxas de distorção idade-série e baixo desempenho dos estudantes.

Pelo exposto, percebe-se quanto é forte o caráter negativo e depreciativo da educação rural. No final da década de 1990, porém, a partir de forte mobilização dos movimentos sociais, é iniciado um movimento para garantir acesso à educação de qualidade para essas pessoas que vivem ou trabalham no campo, é o chamado Movimento Nacional de Educação do Campo. Com a realização da $1^{\text {a }}$ Conferência Nacional por uma Educação Básica do Campo, em 1998, é alterada a nomenclatura usada pelos movimentos sociais e, posteriormente, pelo governo para se referir à educação - antes rural e, agora, do campo.Os autores e participantes desse movimento explicam:

Decidimos utilizar a expressão campo e não a mais usual meio rural, com o objetivo de incluir no processo da Conferência uma reflexão sobre o sentido atual do trabalho camponês e das lutas sociais e culturais dos grupos que hoje tentam garantir a sobrevivência deste trabalho. [...] Embora com esta preocupação mais ampla, temos uma preocupação especial com o resgate do conceito de camponês. Um conceito histórico e político. [...] Essas palavras [caipira, curumba, tabaréu, sertanejo, capiau, lavrador, sitiano, seringueiro, colono, caboclo, caiçara, chapadeiro, catrumano, roceiro, agregado, meeiro, parceiro, parceleiro, sem-terra, assentado] denominam, antes de mais nada, o homem, a mulher, a família que trabalha na terra. São trabalhadores. Seus significados jamais são confundidos com outros personagens do campo: fazendeiros, latifundiários, seringalistas, senhores de engenho, coronéis, estancieiros... As palavras exprimem as diferentes classes sociais (FERNANDES; CERIOLI; CALDART, 2011, p. 25-26, grifos dos autores).

A educação rural, carregada de descaso e de subordinação ao capital, é substituída por uma nova concepção de educação, a educação do campo; esta, para Munarim (2008), carrega diferentes preceitos políticos e pedagógicos. Assim, a mudança seria tamanha que não "suportaria" os mesmos termos como referência.

Com a pressão exercida pelos movimentos sociais, alguns avanços relativos à educação do campo, no que se refere a políticas públicas, foram alcançados, como abertura de cursos para formação inicial e continuada de professores para escolas do campo, legislação para conter o fechamento dessas escolas, programas de aquisição de livros didáticos próprios para educação do campo, incentivo para a educação de jovens e adultos do campo e outros. Muitas dessas políticas estão reunidas no Programa Nacional de Educação do Campo 
(PRONACAMPO), instituído em 2012.Essas conquistas possibilitaram ir além da questão do acesso, surgindo, então, um debate sobre que educação do campo para os povos do campo:

A discussão principal, nesta Conferência [Nacional por uma Educação Básica do Campo], nos parece ser a de como garantir que todas as pessoas do meio rural tenham acesso a uma educação de qualidade, voltada aos interesses da vida do campo. Nisto está em jogo o tipo de escola, a proposta educativa que ali se desenvolve e o vínculo necessário desta educação com uma estratégia específica de desenvolvimento para o campo (FERNANDES; CERIOLI; CALDART, 2011, p. 23).

A especificidade aparece muito forte nas reivindicações dos movimentos sociais. E é o que justifica a contração do: "Não basta ter escolas no campo; quer-se ajudar a construir escolas do campo, ou seja, escolas com um projeto político-pedagógico vinculado às causas, aos desafios, aos sonhos, à história e à cultura do povo trabalhador do campo" (KOLLING; NERY; MOLINA, 1999, p. 18, grifos dos autores).

Nesse mesmo sentido, afirma uma coordenadora pedagógica da Escola Nacional Florestan Fernandes, participante do Movimento dos Trabalhadores Rurais Sem Terra, sobre a especificidade da formação de profissionais para o campo:

Nós queremos formar nossos médicos para estar ali atuando na comunidade,
nós queremos formar nossos agrônomos para ajudar a desenvolver as
cooperativas, as experiências, nós queremos formar nossos professores para
se manter nas escolas do campo. Então, do ponto de vista da necessidade, é
isso que está colocado, como é que vamos avançar na própria organização da
nossa comunidade, nos implica formar pessoas para atuar no projeto de
desenvolvimento dessas comunidades e de atenção às necessidades básicas,
de saúde, educação (BARBOSA, 2014, p. 143).

É, então, nesse contexto que falo da especificidade, também, da matemática na educação do campo. Mas como ser específico? Apresento, a seguir, duas possibilidades de abordagens pedagógicas nesse sentido.

Para tal, retomo o exemplo do professor com boas intenções, que contextualiza suas aulas de matemática com a "realidade" do campo. Ao questionar os estudantes sobre o pagamento da conta de energia elétrica do assentamento rural, ele se depara com uma resposta diferente da que esperava. Uma primeira possibilidade é que esse professor escute o que o estudante tem a dizer - sobre seu modo de resolver a questão da realidade -, perceber a diferença deste e do seu conhecimento matemático e, então, apresentar a matemática da escola - afinal, não é esse o seu papel enquanto professor de matemática?

Lins e Gimenez (1997, p. 18, grifos dos autores) criticam essa abordagem:

O problema [...] é que a idéia de trazer a rua para a escola transforma-se na idéia simplista de usar as coisas da rua para ajudar a fazer com que os alunos aprendam a matemática da escola, isto é, os significados não-matemáticos são vistos apenas como degraus na escada que "sobe" em direção aos significados matemáticos. Mas os exemplos que vimos, ligados às aritméticas da rua e da escola, deixam claro que os significados da rua são diferentes dos 
significados da escola, e não "versões imperfeitas e informais" dos significados matemáticos.

Essa temática foi, também, explorada por Knijnik e Duarte (2010), que problematizaram o enunciado que diz da "importância de trazer a 'realidade' do aluno para as aulas de matemática”. Elas mostraram que esse enunciado não está restrito ao campo da Etnomatemática, mas nele ganha maior visibilidade (p. 881), e que ele se entrelaça com o discurso de que "trazer a 'realidade' do aluno" possibilita dar significado aos conteúdos matemáticos, suscitando seu interesse pela aprendizagem.

Por trás desse discurso, porém, há, além do estabelecimento de hierarquia entre conhecimentos, a diminuição de legitimidade de um deles. Nesse sentido, afirmam Lins e Gimenez (1997, p. 18-19):

[...] um problema com essa idéia é que o que se quer facilitar é a aprendizagem da matemática da escola, e ela se apóia na noção de que a matemática da rua é uma versão imperfeita da matemática da escola. Mas esse não é o único problema nem o maior. A substituição dos significados da rua pelos da escola significa subtrair a legitimidade dos significados da rua.

De todo modo, essa abordagem é relativamente comum na educação do campo. Como mostra Barbosa (2014), a partir de um levantamento realizado em artigos, dissertações, teses, ementas de cursos e com entrevistas, é recorrente a ideia de que "nos currículos das escolas do campo os conteúdos matemáticos devem ser os mesmos de quaisquer outras escolas, mas que é importante partir da realidade camponesa para atingilos" (p. 201).

A segunda possibilidade de abordagem pedagógica é a do reconhecimento da diferença entre conhecimentos, sem hierarquizá-los ou diminuir a legitimidade de um deles. É, então, o reconhecimento de que há matemática do campo e que esse modo de produção de significados é legítimo em seu contexto, podendo, também, ser abordada pelos professores em suas aulas de matemática.Essa abordagem é apresentada por Lins e Gimenez (1997, p. 18):

A alternativa que vamos defender é que o papel da escola é participar da análise e da tematização dos significados da matemática da rua - no caso particular da Educação Matemática - e do desenvolvimento de novos significados, possivelmente matemáticos, que irão coexistir com os significados não-matemáticos, em vez de tentar substituí-los.

Algumas pesquisas têm apresentado propostas desse tipo para a educação do campo.Um exemplo é a pesquisa de Lima e Monteiro (2009) que trata da construção de mapas por agentes comunitárias de saúde do assentamento rural Santa Maria, do município de Água Boa-MT, que cursavam o Ensino Médio, na modalidade de Educação de Jovens e Adultos. 
No contexto dessas trabalhadoras, percebemos que, para iniciarem seus trabalhos, elas recebem da Secretaria Municipal de Saúde (SMS) um mapa geográfico do assentamento para que possam se orientar e definir suas áreas de atuação. Essa divisão é feita de acordo com alguns critérios, como: a distância entre suas casas (ACS) e as moradias que irão atender, a facilidade de acesso, o número de famílias a serem atendidas. [...] Porém, apesar de possuírem esse mapa, essas profissionais organizaram-se espacialmente a partir de suas vivências no local e de referências outras, que diferem das registradas nos mapas oficiais (LIMA; MONTEIRO, 2009, p. 19).

As pesquisadoras solicitaram a essas agentes que representassem suas áreas de trabalho por meio de desenhos e, para o artigo, analisaram dois deles, produzidos por Ideusa. Elas notaram que esses mapas trazem uma "visão sensível do mundo, na qual a presença de elementos da vida social é fortemente indicada, assim como os elementos da natureza local" (LIMA; MONTEIRO, 2009, p. 21). Alguns exemplos disso são o centro do mapa ser sua casa - de onde sai para realizar seu trabalho -, as cores utilizadas para as casas, que dependem da relação afetiva com as famílias, e as distâncias serem representadas pelo tempo da caminhada, o que depende da existência de córregos, pontes e do meio de transporte utilizado.

Afirmo que esse conhecimento (de Ideusa) difere do conhecimento de um professor de matemática ou geografia, quando apresenta regras de escala e de construção de mapas. Como abordar essa diferença em sala de aula?

Um professor de matemática, nesse contexto, poderia, ao invés de partir dessas representações para chegar àquelas da matemática escolar, em hierarquia, como indica a proposta curricular para a educação de jovens e adultos - "Inicialmente, as representações serão construções simples como desenhos e esboços, a partir das quais podem ser trabalhadas representações mais precisas como plantas, até se chegar à interpretação de mapas mais complexos, como o planisfério" (BRASIL, 1997, p. 147) -, problematizar as diferenças e analisar a complexidade envolvida nesses conhecimentos. Ele poderia abordar quais são os aspectos mais importantes de um mapa para aquele que o faz. O tempo para percorrer um trajeto pode ser mais importante que a distância, pois a distância pode não considerar as condições do caminho, as subidas e descidas, o córrego que passa por ali, a ponte que está quebrada etc. E qual a complexidade de se fazer um mapa que leve em consideração esses aspectos? O trecho citado, da proposta curricular, indica haver pouca complexidade em um mapa desse tipo.

A geometria não euclidiana "do táxi” pode surgir nessa discussão proposta pelo professor - mas não como um objetivo inicial ou como uma formalização de algo, mas como um outro tipo de conhecimento - afinal, que mapa real obedece aos postulados dessa geometria? Pensar, por exemplo, em menor distância entre dois pontos é bastante diferente nos seguintes contextos: da geometria euclidiana, da geometria não euclidiana e do mapa de 
Ideusa. Mas quem dirá que há menos complexidade neste último? Àquele que isso disser, sugiro que calcule a menor distância entre dois pontos no assentamento rural Santa Maria!

Como afirma Lins (2008, p. 543):

No compartilhamento da diferença está, eu penso, a mais intensa oportunidade de aprendizagem (para ambos): é apenas no momento em que posso dizer "eu acho que entendo como você está pensando" que se torna legítimo e simétrico dizer, à continuação, "pois eu estou pensando diferente, e gostaria que você tentasse entender como eu estou pensando" (e, note, o "eu" não fica definido, nisso, se é o do professor ou o do aluno ...). Quer dizer, o que se aprende [...] não são conteúdos, técnicas, regras, e sim legitimidades. O que se aprende é a legitimidade de certos modos de produção de significados.

Mas estaria o professor de escolas do campo preparado para lidar com essas diferenças? Que formação teve ele - se é que teve alguma? Os dados do Instituto Nacional de Estudos e Pesquisas Educacionais Anísio Teixeira - INEP (2007) mostram que 65,1\% dos professores de escolas do campo não tinham formação em nível superior. Com a instituição do PRONACAMPO, algumas mudanças ocorreram nesse sentido - especialmente, no que se refere à criação de cursos específicos para formação de professores para atuar em escolas do campo no país.

Dos cursos de Licenciatura em Educação do Campo criados no Brasil, em 2016, 38 habilitavam para a docência em Matemática nos anos finais do Ensino Fundamental e no Ensino Médio. Esses cursos são destinados a quem não possui formação superior e atue como professor em escolas do campo ou que tenha experiência com educação do campo ou seja morador do campo. (SACHS, SANTOS, BORGES, 2016).

Por um lado, esses cursos inovam ao oferecer acesso à educação de nível superior a populações que, historicamente, tiverem esse direito negado; e, por outro lado, inovam em suas propostas de curso.

Uma primeira característica é a implantação do regime de alternância, que deve alternar entre o tempo-escola e o tempo-comunidade. De acordo com Brasil (2012, p. 59), "Entende-se por Tempo-Escola os períodos intensivos de formação presencial no campus universitário e, por Tempo-Comunidade, os períodos intensivos de formação presencial nas comunidades camponesas, com a realização de práticas pedagógicas orientadas”.

Outro aspecto inovador é o fato de esses cursos se relacionarem com os movimentos sociais do campo. Em pesquisa realizada por Santos e Sachs (2016), os autores mostram que os cursos de Licenciatura em Educação do Campo, com habilitação em Matemática, do estado do Paraná, "indicam a demanda, por parte dos movimentos sociais, pela criação dos cursos e estabelecem parcerias com eles, alguns deles explicitam o contexto da região em que o curso está inserido e alguns trazem a atuação dos movimentos sociais com implicações pedagógicas nos cursos” (p. 1). 
Porém, a matemática do campo pouco tem sido abordada nesses cursos. Sachs e Elias (2016) mostram que há algumas tentativas, ainda tímidas, nesse sentido. "O contexto social camponês é trazido em grande parte dos projetos de curso, nos itens objetivo e perfil do egresso, sendo que muitos deles deixam explícita a importância em articular a formação do professor com os saberes próprios do campo" (p. 452). Nos componentes curriculares desses cursos, alguns "deixam clara qual relação estabelecida entre o conteúdo matemático e o contexto camponês" (p. 452) e outros apenas dizem que isso deve acontecer, mas sem dizer como, “seja com itens como 'Aplicações contextualizadas na realidade do campo' em suas ementas ou com seus nomes, como é o caso de Cálculo Diferencial e a vida no campo" (p. 452, grifos dos autores). Mas,

de um modo geral, a Matemática que tem sido priorizada nesses cursos é a chamada Acadêmica, [...] o lugar da Matemática é central e, ainda, [...] na maioria dos casos, as disciplinas de conteúdo matemático vêm dissociadas do contexto social, das disciplinas didático-pedagógicas e da prática do professor (SACHS; ELIAS, 2016, p. 439).

Com essa abordagem, a matemática do campo, mais uma vez, desaparece, tem sua legitimidade subtraída. Alguns dos cursos analisados por Sachs e Elias (2016), por exemplo, "não fazem referência alguma com a vida no campo em suas disciplinas de conteúdo matemático" (p. 448). E, desse modo, se, em um curso específico para o professor que irá atuar em escolas do campo, essas diferentes legitimidades não são reconhecidas e discutidas, como esse futuro professor poderá superar a lógica das aulas tradicionais de matemática, em que apenas um modo de produção de significados é aceito?

Como afirma Lins (2008, p. 547), "penso que a mais intensa oportunidade de aprendizagem acontece no momento em que professor e aluno(s) compreendem que as legitimidades de cada um, naquele momento, são diferentes”. Assim, essas discussões devem fazer parte de cursos de formação - inicial e continuada - de professores. Algumas experiências nesse sentido são inspiradoras, como a relatada por Knijnik (2006), no Curso Magistério de Férias, oferecido no Rio Grande do Sul, para estudantes oriundos de movimentos sociais, e o curso de extensão, proposto por Romulo Campos Lins, "Espaço, aritmética, álgebra e tomada de decisão: um curso de desenvolvimento profissional para professores de matemática", que considerava categorias da vida cotidiana na formação de professores (OLIVEIRA, 2011).

\section{Concluindo}

Este texto se propôs a problematizar a questão posta pelo pesquisador entrevistado: “matemática é matemática, ou tem matemática do campo?”. Para isso, fundamentei-me teoricamente na Etnomatemática e no Modelo dos Campos Semânticos, concluindo que, sim, há matemática do campo. 
Essa matemática do campo difere da matemática da escola, pela própria definição de conhecimento aqui utilizada: "consiste em uma crença-afirmação (o sujeito enuncia algo em que acredita) junto com uma justificação (aquilo que o sujeito entende como lhe autorizando a dizer o que diz)" (LINS, 2012, p. 12).

Assim, refuto o entendimento de que o conhecimento matemático é o mesmo, independentemente do contexto em que se está, como afirmou aquele mesmo pesquisador entrevistado. Concordo com Knijnik (2004, s/p):

$\mathrm{O}$ primeiro alicerce que apresento para meu argumento diz respeito ao entendimento que estou dando à cultura, caracterizando-a como algo que as pessoas, os grupos sociais produzem, que não está de uma vez por todas fixo, determinado, fechado nos seus significados. Cultura aqui não é entendida como algo consolidado, um produto acabado, homogêneo. Este modo de conceituar cultura implica em entendê-la como um terreno conflituado, tenso, em permanente disputa pela imposição de significados. Também implica questionar aquele velho chavão: "Nossa função como professoras e professores é trazer para o currículo, ensinar na escola a Matemática que foi acumulada pela humanidade.” Exatamente isto está em jogo para a Etnomatemática: qual Matemática que tem sido chamada de "Matemática acumulada pela humanidade"? Diferentemente de posições defendidas pela "Pedagogia crítico-social dos conteúdos", argumento que a assim chamada "Matemática acumulada pela humanidade" é somente uma parcela de uma ampla e heterogênea produção, precisamente a parcela produzida pelos grupos hegemônicos. Que grupos têm ficado silenciados, escondidos, não representados no currículo escolar, também na área da Matemática?

Esses grupos silenciados, escondidos, não representados no currículo escolar devem ter seus modos de produção de significado legitimados, também, na escola. E é por isso que a escola do campo deve abordar a especificidade da matemática do campo - o que vale para outras especificidades, do mesmo modo.

Como fazer isso em uma escola do campo é uma questão importante e apresentei, aqui, duas abordagens possíveis. A primeira delas - bastante recorrente na literatura - é partir desse outro conhecimento - a matemática do campo - para atingir o conhecimento presente nos currículos escolares - a matemática escolar. Porém, como afirmam Lins e Gimenez (1997, p. 19), “A idéia de valorizar o que a rua sabe apenas como ponto de partida faz parte de um discurso que, embora pareça razoável do ponto de vista didático, é perverso do ponto de vista cultural”.

A segunda abordagem é o que Lins (2008) chama de compartilhamento da diferença, em que ambos - professores e estudantes - se dispõem a compreender a forma que o outro está pensando sobre alguma situação. Aprende-se, assim, legitimidades de outros modos de produção de significados. Para isso, é preciso alguns movimentos de contraconduta ${ }^{8}$ por parte do professor.

8 Para Foucault (2008), o termo contracondutaestá "no sentido de luta contra os procedimentos postos em prática para conduzir os outros" (p. 266). 
Um deles envolve abandonar a ideia de que "tudo é matemática" ou de que "a matemática está em tudo". Quando se olha para qualquer situação cotidiana em busca de encontrar a matemática da escola, outras legitimidades são diminuídas, pois a matemática que não a da escola passa a ser uma versão imperfeita desta. Muitas pesquisas em Etnomatemática, porém, ainda insistem nesse caminho. É comum, no que se refere à matemática na educação do campo, o trabalho pedagógico com hortas. Procurar nelas formas geométricas é um chavão! Situação semelhante é exemplificada por Lins (1999), ao falar do trabalho com pipas em sala de aula, em que os professores propõem cálculo de área, de perímetro, da perpendicularidade etc., mas pouco falam sobre o que realmente importa para quem empina pipas: a capacidade de voo e a beleza. Para quem lida com a roça, o que importa na produção de uma horta? Aposto que não sejam os ângulos internos formados pelo polígono que o olho do professor de matemática insiste em ver naquela horta!

Outro movimento de contraconduta está em deixar de olhar para os estudantes pela falta, ou seja, por aquilo que eles ainda não sabem, mas que deveriam saber. Como afirma Lins (2012, p. 11), quando um estudante responde algo, diferente daquilo que o professor espera, certamente ele não teve um curto-circuito cerebral; ele está pensando em alguma coisa e o professor pode tentar entender essa outra forma de pensar, abordando-a em suas aulas - e, não, após as aulas, quando for "tirar as dúvidas" desse estudante. Mas, para isso, o professor precisa sair do pedestal em que se colocou. Compreender novos modos de produção de significados não é tarefa fácil - pergunte para aquele estudante que insiste em não compreender aquilo que você, professor, explica em suas aulas. O professor deve estar disposto a aprender outras legitimidades.

Por fim, mais um movimento de contraconduta necessário, muito bem explorado por GelsaKnijnik, em sua palestra durante o XII Encontro Nacional de Educação Matemática: “uma não (completa) sujeição às avaliações de larga escala”. Essas avaliações acabam por inverter a ordem das coisas e determinam, via de regra, o que o professor deve abordar em suas aulas. O professor se preocupa com os resultados na Prova Brasil, no ENEM, nos vestibulares etc. e, por conta disso, veem seu tempo em sala de aula reduzido a praticamente nada, diante de toda a lista de conteúdos que tem a cumprir. É comum escutarmos de professores de matemática reclamações sobre as poucas aulas que há de matemática: “só duas aulas semanais no Ensino Médio!”. Quando digo que outras áreas do conhecimento têm a mesma ou menor carga horária - notadamente as áreas das ciências humanas -, sempre escuto algo que eleva a importância da matemática diante das demais. Por que seria a matemática mais importante que a sociologia, por exemplo? Possivelmente muitos argumentos para essa defesa sejam vazios ("a matemática ajuda a desenvolver o raciocínio lógico" - e a sociologia, não?), mas um é irrefutável: as avaliações em larga escala exigem que os estudantes conheçam muitas técnicas matemáticas, sendo que algumas dessas 
avaliações só "avaliam” matemática e língua portuguesa. Por esse e outros motivos (como o que acontece em algumas secretarias estaduais: bônus salarial para o professor, dependendo dos resultados das avaliações), o professor tem fortes razões para se preocupar. Porém, essa sujeição às avaliações escolares tem consequências cruéis, que envolvem a classificação e a exclusão.

Concluo este texto desafiando os professores de matemática em escolas do campo a repensarem suas práticas, considerando, também, em suas aulas a matemática do campo, pois matemática não é matemática.

\section{Referências}

BARBOSA, L. N. S. C. Entendimentos a respeito da matemática na educação do campo: questões sobre currículo. 2014. 234 f. Tese (Doutorado em Educação Matemática) - Universidade Estadual Paulista “Júlio de Mesquita Filho”, Rio Claro, 2014.

BOCASANTA, D. M. Crianças catadoras e práticas matemáticas. In: WANDERER, F.; KNIJNIK, G. Educação Matemática e Sociedade. São Paulo: Livraria da Física, 2016. p. 51-74.

BRASIL. Ministério da Educação e do Desporto. Educação de Jovens e Adultos: proposta curricular para o $1^{\mathrm{o}}$ segmento do ensino fundamental. Brasília: MEC, 1997.

BRASIL. Ministério da Educação. Secretaria de Educação Continuada, Alfabetização, Diversidade e Inclusão. Edital de Chamada Pública $n^{0}$ 2, de 31 de agosto de 2012. Diário Oficial da União, Brasília, 5 set. 2012. Seção 3, p. 59-60.

D’AMBROSIO, U. Etnomatemática e Educação. In: KNIJNIK, G.; WANDERER, F.; OLIVEIRA, C. J. Etnomatemática: currículo e formação de professores. Santa Cruz do Sul: EDUNISC, 2004. p. 39-52.

FERNANDES, B. M.; CERIOLI, P. R.; CALDART, R. S. Primeira Conferência Nacional "Por Uma Educação Básica do Campo" (Texto preparatório). In: ARROYO, M. G.; CAldart, R. S.; MOlina, M. C. Por uma Educação do Campo. 5 ed. Petrópolis: Vozes, 2011. p. 19-63.

FOUCAULT, M. Segurança, território, população: curso dado no Collège de France (1977-1978). Tradução de Eduardo Brandão. São Paulo: Martins Fontes, 2008

HOUAISS, A. Conhecimento. In: . Houaiss Eletrônico. Rio de Janeiro: Objetiva, 2009. CD-ROM.

INSTITUTO NACIONAL DE ESTUDOS E PESQUISAS EDUCACIONAIS ANÍSIO TEIXEIRA. Panorama da educação do campo. Brasília: Instituto Nacional de Estudos e Pesquisas Educacionais Anísio Teixeira, 2007. 
KNIJNIK, G. Educação matemática, culturas e conhecimentos na luta pela terra. Santa Cruz do Sul: EDUNISC, 2006.

KNIJNIK, G. Etnomatemática e politicidade da Educação Matemática. In: CONGRESSO BRASILEIRO DE ETNOMATEMÁTICA, 2., 2004, Natal. Anais... Natal, 2004. Disponível em: $\quad$ http://www2.fe.usp.br/ etnomat/siteantigo/anais/GelsaKnijnik.html. Acesso em 26 de julho de 2016.

KNIJNIK, G.; DUARTE, C. G. Entrelaçamentos e Dispersões de Enunciados no Discurso da Educação Matemática Escolar: um estudo sobre a importância de trazer a "realidade" do aluno para as aulas de matemática. Bolema, Rio Claro, v. 23, n. 37, p. 863-886, dez. 2010.

KOlling, E. J.; NERY, I. I. J.; MOLINA, M. C. Por uma educação básica do campo (memória). Brasília: Articulação Nacional por uma Educação do Campo, 1999.

LEITE, S. C. Escola rural: urbanização e políticas educacionais. São Paulo: Cortez, 1999.

LIMA, M. J.; MONTEIRO, A. Práticas Sociais de Localização e Mapeamento: uma discussão curricular sobre o conceito de escala. Bolema, Rio Claro, v. 22, n. 32, p. 1-28, abr. 2009.

LINS, R. C. A diferença como oportunidade para aprender. In: PERES, E.; TRAVERSINI, C.; EGGERT, E.; BONIN, I. Trajetórias e processos de ensinar e aprender: sujeitos, currículos e culturas. Porto Alegre: EdiPUCRS, 2008. p. 530-550.

LINS, R. C. GIMENEZ, J. Perspectivas em Aritmética e Álgebra para o século XXI. Campinas: Papirus, 1997.

LINS, R. C. O Modelo dos Campos Semânticos: estabelecimentos e notas de teorizações. In: ANGElO, C. L.; BARBOSA, E. P.; VIOLA DOS SANTOS, J. R.; DANTAS, S. C.; OliveirA, V. C. A. Modelo dos Campos Semânticos e Educação Matemática: 20 anos de história. São Paulo: Midiograf, 2012. p. 11-30.

LINS, R. C. Por que discutir teoria do conhecimento é relevante para a Educação Matemática? In: BICUDO, M. A. V. Pesquisa em Educação Matemática: concepções e perspectivas. São Paulo: UNESP, 1999. p. 75-94.

MONTEIRO, A. A Etnomatemática em cenários de escolarização: alguns elementos de reflexão. In: KNIJNIK, G; WANDERER, F.; OLIVEIRA, C. J. (Org.) Etnomatemática: currículo e formação de professores. Santa Cruz do Sul: EDUNISC, 2004. p. 432-446.

MUNARIM, A. Movimento Nacional de Educação do Campo: uma trajetória em construção. In: REUNIÃO ANUAL DA ASSOCIAÇÃO NACIONAL DE PÓS-GRADUAÇÃO E PESQUISA EM EDUCAÇÃO, 31., 2008, Caxambu. Anais...Caxambu, 2008, p. 1-17. Disponível em: http://31reuniao.anped.org.br/1trabalho/GTo3-4244--Int.pdf. Acesso em 29 de julho de 2016. 
OLIVEIRA, V. C. A. Uma leitura sobre formação continuada de professores de matemática fundamentada em uma categoria da vida cotidiana. 2011. 207 f. Tese (Doutorado em Educação Matemática) - Universidade Estadual Paulista “Júlio de Mesquita Filho", Rio Claro, 2011.

PERAINO, M. A. C. Adolescente com altas habilidades/superdotação de umassentamento rural: um estudo de caso. 2007. 104 f. Dissertação (Mestrado em Psicologia) -Universidade Católica Dom Bosco, Campo Grande, 2007.

SACHS, L.; ELIAS, H. R. A Formação Matemática nos Cursos de Licenciatura em Educação do Campo.Bolema, Rio Claro, v. 30, n. 55, p. 439-454, ago. 2016.

SACHS, L.; SANTOS, J. G. C.; BORGES, L. G. A presença da Etnomatemática em Cursos de Licenciatura em Educação do Campo. In: CONGRESSO BRASILEIRO DE ETNOMATEMÁTICA, 5., 2016, Goiânia. Resumos... Goiânia: UFG, 2016. p. 57.

SANTOS, J. G. C.; SACHS, L. Relação entre movimentos sociais e cursos de Licenciatura em Educação do Campo com habilitação em Matemática do Paraná. In: ENCONTRO NACIONAL DE EDUCAÇÃo MATEMÁTICA, 12., 2016, São Paulo. Anais... São Paulo, 2016, p. 1-12. Disponível em: http://sbempe.cpanelo179.hospedagemdesites.ws/enem2016/anais/pdf/6487_292 4_ID.pdf. Acesso em 31 de julho de 2016.

\section{Bibliografia Resumida}

Línlya Sachs, licenciada e bacharel em Matemática, pela Universidade de São Paulo (USP/São Carlos), mestre em Ensino de Ciências e Educação Matemática, pela Universidade Estadual de Londrina (UEL) e doutora em Educação Matemática pela Universidade Estadual Paulista "Júlio de Mesquita Filho" (Unesp/Rio Claro). Professora da Universidade Tecnológica Federal do Paraná (UTFPR/Cornélio Procópio).

Contato:linlyasachs@yahoo.com.br.

Currículo Lattes:http://lattes.cnpq.br/7491007150992831. 